\title{
Análise das inter-relações das patentes das universidades sob a perspectiva de mercado
}

\section{Analysis of inter-relationships of university patents under the market perspective}

\author{
Antônio Martins Oliveira Junior $\quad$ Dr. em Engenharia Química. Universidade Federal de Sergipe (UFS) - Brasil. \\ amartins.junior@gmail.com \\ Jair Jefferson Maia de Almeida Me. em Propriedade Intelectual. Universidade Federal de Sergipe (UFS) - Brasil. \\ jefferson.maia88@gmail.com.
}

\section{RESUMO}

A Lei de Inovação 10.973/2004 propiciou às universidades o estímulo necessário para a promoção do desenvolvimento econômico do país. Consequentemente, permitiu aos professores pesquisadores das universidades públicas produzirem inovações como resultado de suas pesquisas, por meio do suporte à pesquisa e à transferência de tecnologia. Dessa maneira, faz-se necessário que haja o desenvolvimento da propriedade intelectual alinhado com o mercado. Para isso, existe a necessidade de uma interação entre os detentores do conhecimento e os centros produtivos. Sendo assim, esse artigo trata de uma pesquisa exploratória sobre a temática, de forma que gere uma discussão no meio acadêmico sobre a necessidade de desenvolver tecnologias que de fato possam ser incorporadas pelo mercado. Além disso, possui uma abordagem qualitativa na construção do referencial teórico, e quantitativa na análise dos dados, sendo que estes foram recuperados na base do INPI e exportados para o Microsoft Excel, para o tratamento e análises das informações. Após as padronizações de acordo com a Classificação Internacional de Patentes (IPC) e por estado, os dados foram interpretados e inter-relacionados com o contexto da economia de cada estado da região nordeste, por meio de dados secundários. No entanto, ficou evidenciado que apesar das instituições de ensino buscarem solicitar a proteção de seus ativos, tais tecnologias não possuem uma relação com as demandas dos centros produtivos.

Palavras-chave: Mercado. Propriedade intelectual. Patente. Universidade.

\begin{abstract}
The Law of Innovation 10.973/2004, provided universities with the incentive needed for the promotion of the country's economic development. Through the support to research and transference of technologies, it allowed research professors of public universities to produce innovation. For that purpose, what is needed is the development of intellectual property aligned with the market. Therefore, there has to be an interchange between holders of knowledge and knowledge producing centers. This article is an exploratory research on the theme aiming at a discussion in the academic world about the need to develop technologies that can in fact be incorporated in the market. It is qualitative in approach in the construction of theoretical reference, and quantitative in data analysis. Data were recovered in the base of INPI and exported to Microsoft Excel for treatment and analysis. After standardization according to the International Patent Classification (IPC), theses data were analyzed, interpreted and interrelated by state according to the economy of each of these states of the Northeast region by means of secondary data. It was observed that, although the sources of education institutions seek protection of their assets, these do not relate with the demands of the productive centers.
\end{abstract}

Keywords: Marketplace. Intellectual property. Patent. University.

Recebido em 30/01/2019. Aprovado em 26/03/2019. Avaliado pelo sistema double blind peer review. Publicado conforme normas da ABNT. http://dx.doi.org/10.22279/navus.2019.v9n4.p139-160.907 


\section{INTRODUÇÃO}

O papel da inovação no desenvolvimento tecnológico e econômico dos países, especialmente a partir do século XX, tem impulsionado a discussão sobre a importância da gestão da propriedade intelectual (PI). Diversas perspectivas de análise da PI buscam o melhor aproveitamento de novas tecnologias desenvolvidas tanto por instituições públicas quanto por instituições privadas a serem aplicadas no mercado. Partindo desse pressuposto, é importante destacar que as universidades ganharam destaque no desenvolvimento de novas tecnologias a partir da promulgação da Lei de Inovação Tecnológica (LIT) de n. ${ }^{\circ}$ 10.973/2004. Esta basicamente dispõe sobre medidas de incentivo à inovação e à pesquisa científica e tecnológica no ambiente produtivo, com vistas à capacitação tecnológica, ao alcance da autonomia tecnológica e ao desenvolvimento do sistema produtivo nacional e regional do país (BRASIL, 2004).

Diante disso, a importância das universidades e suas pesquisas são amplamente reconhecidas, pois o objetivo principal sempre foi o desenvolvimento de novas tecnologias. Contudo, mais recentemente ocorre uma mudança crescente para a inclusão da comercialização nas atividades. Porquanto, é notório saber que os professores das universidades produzem inovações como resultado de atividades de pesquisa que, por sua vez, podem ser explorados comercialmente (AB AZIZ; HARRIS; AB AZIZ, 2012). No entanto, a transformação de pesquisa e desenvolvimento em comercialização é um caminho cheio de armadilhas, dentre as quais de forma dedutiva podem-se destacar: a falta de um fortalecimento de uma política de cultura de proteção da $\mathrm{Pl}$; uma falta de estratégias de inovações voltadas para o mercado; e projetos tecnológicos dentro das universidades que sejam concretos, industrializáveis e comercializáveis (BRITTES; SALLES FILHO; PFITZNER, 2016).

Torna-se relevante, portanto, apreender que no contexto competitivo e globalizado em que as empresas e as universidades públicas federais se fazem presentes, a gestão da propriedade intelectual e a inovação tecnológica transformaram-se em um poderoso instrumento para o incremento econômico, pois o conhecimento proveniente das universidades brasileiras representa uma fonte de informação e de geração de novas tecnologias. Ou seja, a transferência de tecnologia entre as universidades e o setor produtivo consiste em um caminho alternativo para o alcance de um patamar tecnológico avançado das empresas nacionais (GARNICA; TORKOMIAN, 2009).

Logo, o conhecimento e a inovação são fatores imprescindíveis como fontes do progresso tecnológico e consequentemente do desenvolvimento da propriedade intelectual com o alinhamento ao mercado. Diante deste cenário, o objetivo da pesquisa é analisar as inter-relações das patentes das universidades públicas federais do nordeste brasileiro sob a perspectiva do mercado.

\section{REFERENCIAL TEÓRICO}

A patente é um título de propriedade com período definido e concedido pelo Estado que permite ao seu titular o monopólio da invenção, excluindo aqueles não autorizados de atos relativos à matéria protegida. Como contrapartida, o inventor divulga a informação tecnológica da invenção depois de decorrido o prazo de proteção, para que a inovação possa ser utilizada por toda a sociedade. Ou seja, a propriedade intelectual em seu sentido amplo refere-se à proteção dos criadores sobre suas criações, oferecendo ao titular da PI a possibilidade de usar livremente sua invenção, desde que seu uso não interfira o direito de outrem ou até mesmo à lei, sendo que o titular da invenção pode impedir que alguém venha utilizá-la sem a sua anuência. De forma mais específica, Andrade et al. $(2017$, p. 3) afirmam que a propriedade intelectual faz parte do "ramo jurídico que lida com a proteção legal concedida a todas as criações da mente humana, como invenções, obras literárias e artísticas, símbolos, nomes e imagens usadas com propósito". É válido ressaltar que dentre os direitos relativos à propriedade intelectual com legislação no Brasil, compreende-se: a propriedade industrial, os direitos do autor e conexos, e a proteção sui generis. Sendo que, no Brasil, fica a cargo do Instituto Nacional de Propriedade Industrial (INPI) a análise de: patentes, marcas, indicações geográficas e desenho industrial, todos dentro do escopo da propriedade industrial. Além disso, o INPI analisa os programas de computador e topografia de circuito integrado. 
No Brasil, dentro da finalidade da PI, o que ganha maior destaque entre as universidades públicas federais brasileiras é a patente de invenção ou de utilidade. Porquanto, esta é uma forma especial e representa uma fonte rica de conhecimento gerado nestas instituições, sendo o resultado do desenvolvimento das pesquisas de novas tecnologias. Logo, diante de uma necessidade crescente de desenvolvimento tecnológico, vêm-se exigindo dos atores envolvidos, especialmente das universidades públicas federais, a geração e a difusão de inovações tecnológicas. Uma das maneiras de promover o desenvolvimento tecnológico com vistas para o mercado é por meio da criação de uma gestão da PI que permita a interação entre as instituições de ensino de pesquisa e as empresas. Essa interação com o mercado implica na existência de uma gestão da propriedade intelectual sob a perspectiva estratégica das inter-relações com o mercado.

Logo, a gestão da propriedade intelectual não se trata apenas de proteger os ativos intangíveis das universidades, mas também de ter condições de negociá-las através da transferência da PI, e assim gerar receitas para as instituições de ensino. Com isso, os professores e pesquisadores devem estar sempre atentos aos novos processos tecnológicos em suas áreas de atuação, o que requer planejar atuações no campo da pesquisa científica e tecnológica, como forma de suscitar conhecimentos e tecnologias que possam ser incorporadas ao mercado.

Através dessa perspectiva, Fujino e Stal (2007) afirmam que no país há um crescente aumento da consciência sobre a necessidade de transferir aos centros produtivos os resultados da pesquisa financiada através dos recursos públicos. No entanto, essa consciência ainda não é acompanhada por atuações que de fato viabilizem a devida transferência, uma vez que um bom resultado não é suficiente para iniciar o processo de comercialização. Porquanto, é preciso demonstrar que é possível transformá-lo em inovação. Por conseguinte, para que haja um desenvolvimento de novas tecnologias com vistas para o mercado, é necessário que as universidades tenham uma gestão da propriedade intelectual que assegure a proteção dos ativos de $\mathrm{PI}$, mas alicerçando-se em uma gestão estratégica que envolve planejamento, organização e execução de atividades ligadas à PI aplicáveis aos produtos e processos inovadores (LOIOLA; MASCARENHAS, 2013). Entretanto, a transformação de pesquisa e desenvolvimento na comercialização é um caminho cheio de muitos obstáculos, que somente serão superados com a efetiva gestão estratégica da propriedade intelectual, alinhado com a aproximação com as demandas do mercado.

\section{METODOLOGIA}

Foi desenvolvida uma pesquisa exploratória fundamentada no levantamento bibliográfico, pois, segundo Cervo, Bervian e Silva (2007, p. 60) "a pesquisa bibliográfica procura explicar um problema a partir de referências teóricas publicadas em artigos, livros, dissertações e teses". A pesquisa apresenta um caráter qualitativo, apresentando o referencial teórico, pois "[...] se preocupa, nas ciências sociais, com um nível de realidade que não pode ser quantificado" (MINAYO, 2002, p. 21). Já Prodanov e Freitas (2013, p. 70) afirmam que a pesquisa qualitativa "considera que há uma relação dinâmica entre o mundo real e o sujeito, isto é, um vínculo indissociável entre o mundo objetivo e a subjetividade do sujeito que não pode ser traduzido em números". Portanto, este não requer o uso de métodos e técnicas estatísticas. Além disso, o artigo tem uma abordagem quantitativa sobre os dados, corroborando com a ideia de Prodanov e Freitas (2013, p. 69), que afirmam que a pesquisa quantitativa "considera que tudo pode ser quantificável, o que significa traduzir em números opiniões e informações para classificá-las e analisá-las. Requer o uso de recursos e de técnicas estatísticas".

Sendo assim, em atendimento ao objetivo proposto, os dados coletados foram recuperados junto à base de do Instituto Nacional de Propriedade Industrial (INPI) no mês de maio de 2018. É importante ressaltar que a escolha da base de dados do INPI se deu em razão de ser o órgão nacional onde as universidades públicas federais depositam seus pedidos de solicitações de patentes.

Este artigo foi resultado de uma pesquisa conduzida através do INPI. Ressalta-se que foram pesquisadas todas as solicitações de patentes depositadas e/ou publicadas nas 18 (dezoito) universidades públicas federais existentes no nordeste brasileiro, e para isso não foram utilizadas restrições temporais na coleta de dados. Salientando que a escolha das universidades justifica-se pelo fato de serem destaque no 
cenário nacional e principalmente regional, porquanto promovem o conhecimento e a produção científica na região nordeste. No entanto, esse é um local que ainda sofre com questões sociais e econômicas. Dessa forma, ao estudar as inter-relações das patentes das universidades sob a perspectiva de mercado, o estudo revela a contribuição que estas instituições estão fornecendo para o desenvolvimento social, econômico e tecnológico por meio das tecnologias que elas desenvolvem e das estratégias que possibilita a gestão do conhecimento e a transformação desse conhecimento em produtos e processos que fortaleçam o desenvolvimento da região.

O método da coleta de dados foi através do CNPJ (Cadastro Nacional de Pessoa Jurídica) das universidades no campo "Pesquisa Avançada". Sendo que os dados coletados na base do INPI foram exportados para o software Microsoft Excel para o tratamento e análises das informações. Após as padronizações de acordo com a Classificação Internacional de Patentes (IPC - International Patent Classification) e por estado, os dados foram registrados, analisados e interpretados. No que tange à interpretação para fazer essa inter-relação com o mercado, foi feita uma análise das patentes e posteriormente busca por meio de dados secundários (dados econômicos, através de site oficiais) de cada estado e, assim, identificando se existem uma inter-relação ou se estão sendo desenvolvidas tecnologias que não estão dentro do contexto dos estados.

\section{ANÁLISE E RESULTADOS}

A escolha dessas universidades justifica-se por todas estarem situadas na mesma região, o que torna a análise mais eficaz, pois os nove estados citados possuem características sociais, ambientais e econômicas muito similares.

Para atender o objetivo deste artigo, foram realizadas buscas de patentes no site do Instituto Nacional de Propriedade Industrial (www.inpi.gov.br), das 18 (dezoito) universidades públicas federais existentes no nordeste do Brasil, cujos resultados apontaram as emissões de 1.075 (Um mil e setenta e cinco) patentes, e posteriormente divididos de acordo com a Classificação Internacional de Patentes (IPC), sendo: Seção A Necessidades Humanas; Seção B - Operações de Processamento e Transporte; Seção C - Química e Metalurgia; Seção D - Têxteis e Papel; Seção E - Construções Fixas; Seção F - Engenharia Mecânica, Iluminação, Aquecimento, Armas e Explosão; Seção G - Física; e Seção H - Eletricidade. Do total de documentos recuperados no site do INPI, pode-se observar na Figura 1 a distribuição de patentes das universidades públicas federais segregadas por estados.

Figura 1 - Número de Patentes das Universidade Públicas Federais dividida por Estado

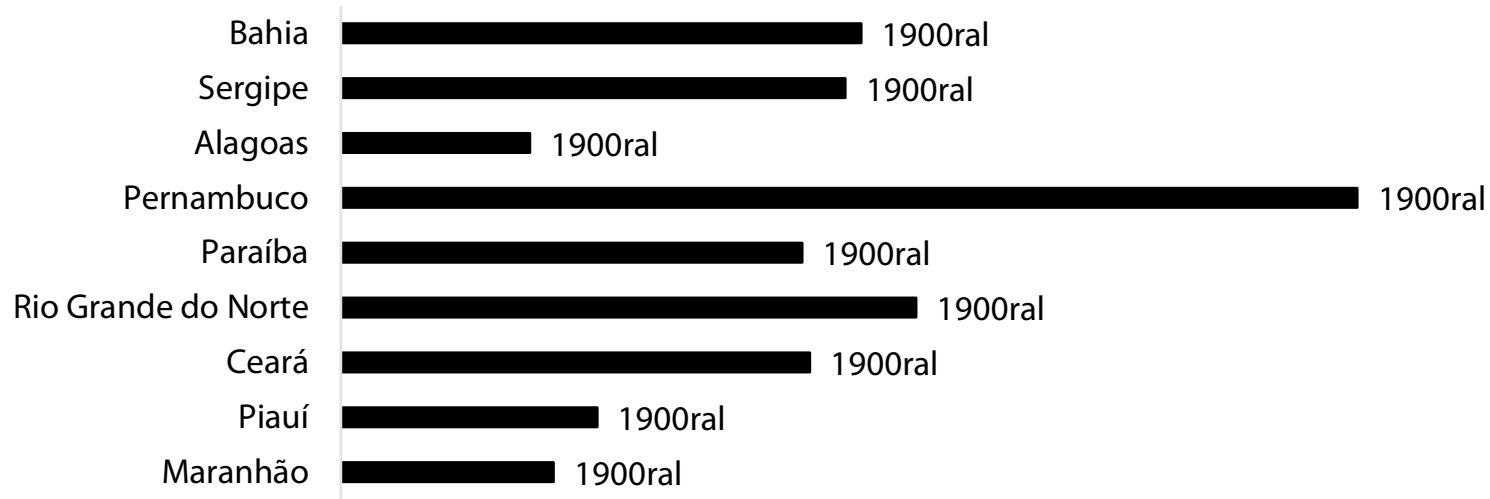

Fonte: Elaboração própria (2018).

Cabe ressaltar que na região nordeste, o estado que possui maior destaque é Pernambuco, pois detém 258 ou $24 \%$ das solicitações de patentes, seguidos do Rio Grande do Norte e Bahia, respectivamente, com 146 ou $13,6 \%$ e 132 ou 12,3\% do total de patentes. Tal quantidade de patentes justifica-se devido a estes estados possuírem universidades tradicionais no cenário nacional, tais como a UFPE, a UFRN e a UFBA, todas 
estas com alta capacidade de desenvolvimento de novas tecnologias. Por sua vez, na Tabela 1 observa-se esse total de solicitações de patentes classificados de acordo com o IPC.

Tabela 1 - Número de Patentes das Universidades Públicas Federais de acordo com a Classificação Internacional de Patentes

\begin{tabular}{|c|c|c|c|}
\hline & Classificação das Patentes & Patentes & Percentual \\
\hline A & Necessidades Humanas & 466 & $43,35 \%$ \\
\hline B & Operações de Processamento; Transporte & 91 & $8,47 \%$ \\
\hline C & Química; Metalurgia & 309 & $28,74 \%$ \\
\hline $\mathrm{D}$ & Têxteis; Papel & 2 & $0,19 \%$ \\
\hline $\mathrm{E}$ & Construções Fixas & 9 & $0,84 \%$ \\
\hline $\mathrm{F}$ & \multicolumn{2}{|c|}{ Explosão } & $2,60 \%$ \\
\hline G & Física & 134 & $12,47 \%$ \\
\hline $\mathrm{H}$ & Eletricidade & 36 & $3,35 \%$ \\
\hline & Total & 1075 & $100,00 \%$ \\
\hline
\end{tabular}

Fonte: Elaboração própria (2018).

Destaca-se que existe uma predominância na Seção A, com um total de $43,35 \%$ das solicitações de patentes. Percebe-se, dessa forma, que os pesquisadores das universidades da região nordeste, em sua grande maioria, desenvolvem novas tecnologias com foco na área de necessidades humanas, pois supostamente tal seção possui um caráter multidisciplinar com aplicação em diferentes setores da economia. Então, a partir das observações e análises desse estudo, é possível identificar se existe ou não uma inter-relação entre as patentes das universidades públicas federais do nordeste e o mercado, de acordo com os aspectos a seguir.

\subsection{Análise das patentes no estado de Alagoas}

O estado possui apenas a Universidade Federal de Alagoas (UFAL), a qual é titular de 48 solicitações de patentes publicadas, sendo válido ressaltar que nenhuma patente foi concedida. Na Figura 2 é apresentado o total de solicitações classificadas de acordo com IPC, e observa-se um destaque para a Seção A Necessidades Humanas, pois possui $54,2 \%$ do total de patentes, e que somado com a seção C - Química e Metalurgia, esse percentual torna-se ainda mais dominante, por possuir $95,9 \%$ das solicitações de patentes, o que torna possível afirmar que os pesquisadores dessa universidade possuem um perfil de desenvolver inovações tecnológicas voltadas para essas duas áreas do conhecimento. 
Figura 2 - Número de Patentes da Universidade Pública Federal de Alagoas de acordo com a Classificação Internacional de Patentes

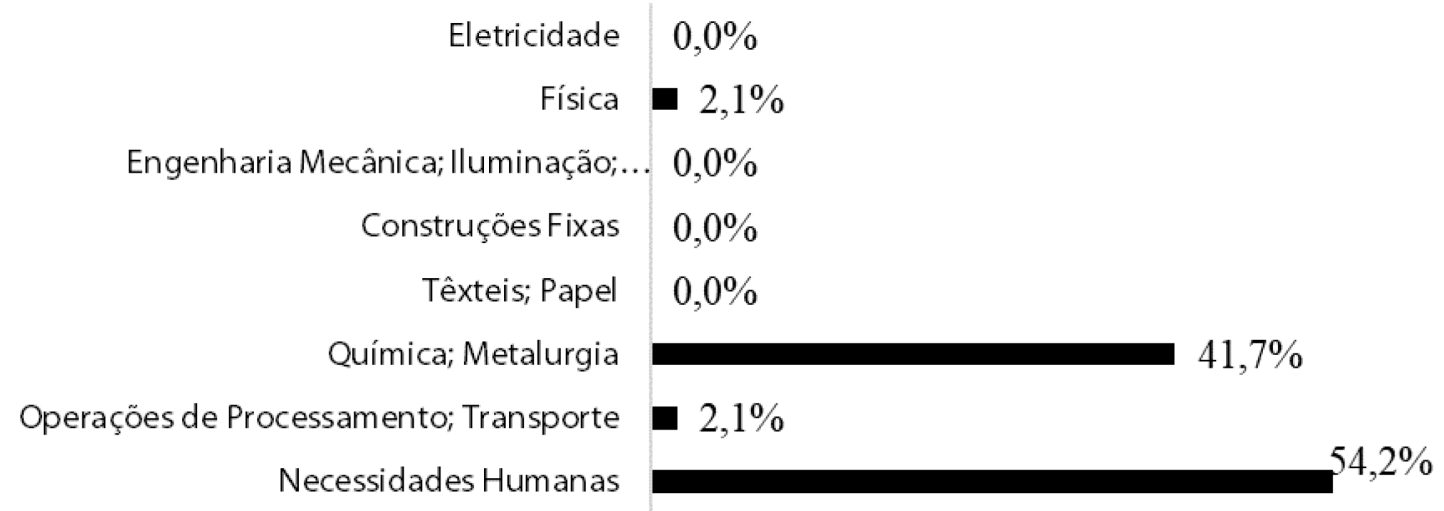

Fonte: Elaboração própria (2018).

Ainda dentro do contexto das análises dos documentos de patentes, observa-se na Figura 3 a distribuição dos maiores percentuais da Seção A, de acordo com as suas subseções.

Figura 3 - Percentual de Patentes da Universidade Pública Federal de Alagoas de acordo com as subseções do IPC

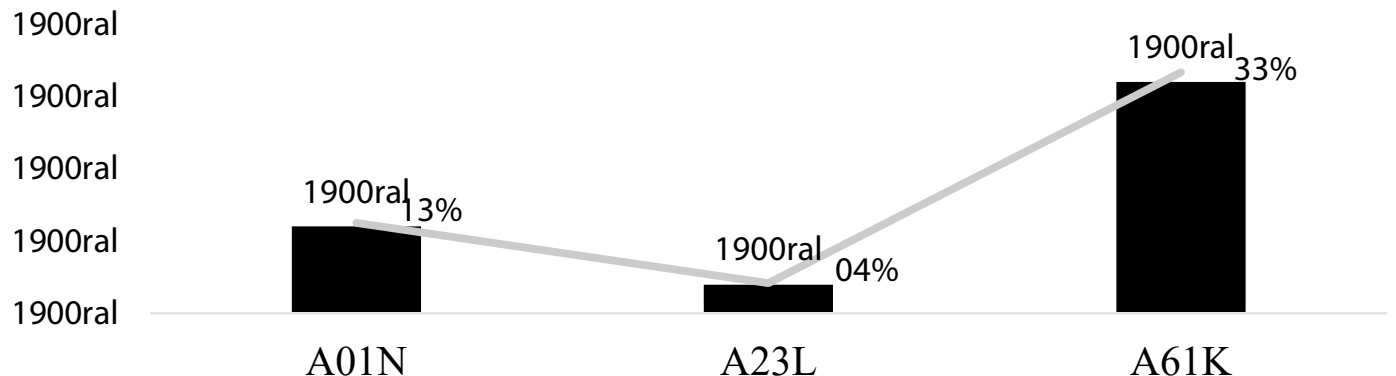

- Série1 Série2

Fonte: Elaboração própria (2018).

É perceptível que existe uma concentração na subseção $A 61 \mathrm{~K}$, com um total de 33,3\% do total das necessidades humanas, sendo que pode-se concluir que os pesquisadores dessa universidade buscam desenvolver novas tecnologias voltadas para preparações para finalidade médicas, odontológicas e higiênicas. Todavia, ao analisar a tendência de pesquisa da universidade em comparação com a economia do estado de Alagoas, pode-se constatar que tal instituição não tem tendência de pesquisas desenvolvidas com vistas ao mercado. Porquanto, o estado é dividido em 9 sub-regiões com características peculiares que lhes conferem uma diversidade na composição do seu Produto Interno Bruno (PIB). No entanto, de acordo com a SEPLAG, SINC e GGEO com dados referentes ao ano de 2014, existe uma predominância no setor agropecuário em praticamente todas as sub-regiões do estado. Sendo que, entre os principais produtos agrícolas cultivados, encontram-se cana-de-açúcar, mandioca e coco, além da criação de animais, tais como: bovinos, galináceos e pesca. Além disso, no setor industrial, de acordo com dados do governo do estado, dentre as atividades que mais contribuem para o desempenho econômico de Alagoas são: indústria açucareira, química e extração e tratamento de minerais, ratificando que o estado e a universidade estão em lados opostos no desenvolvimento da economia. 


\subsection{Análise das patentes no estado de Sergipe}

O estado possui apenas a Universidade Federal de Sergipe (UFS), a qual é titular de 128 solicitações de patentes publicadas, sendo que a universidade possui 8 (oito) patentes concedidas, das quais metade já está em domínio público. Na Figura 4 é apresentado o total de solicitações classificadas de acordo com IPC.

Figura 4 - Número de Patentes da Universidade Pública Federal de Sergipe de acordo com a Classificação Internacional de Patentes

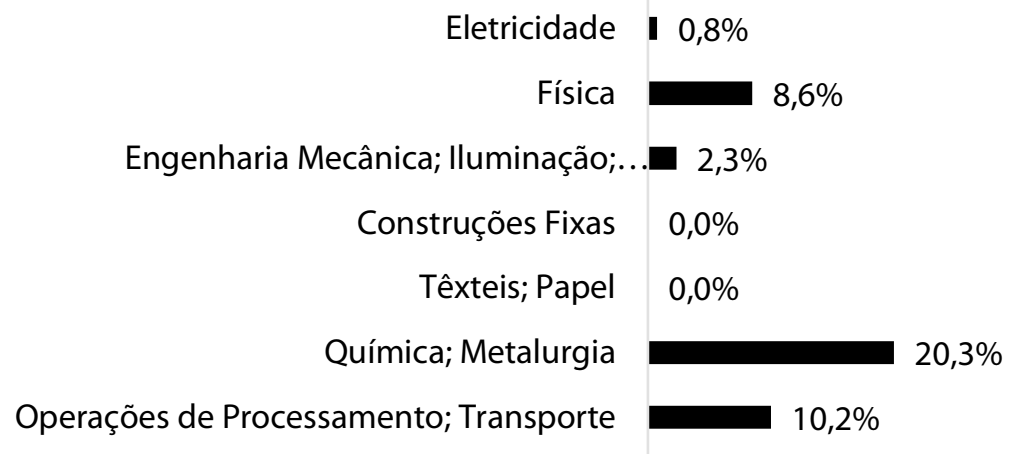

Necessidades Humanas

Fonte: Elaboração própria (2018).

Nesta universidade, observa-se que a Seção A - Necessidades Humanas possui $57,8 \%$ do total de patentes, e que somando com as outras duas primeiras seções ( $B$ - Operações de Processamento e Transporte e C - Química e Metalurgia) esse percentual torna-se ainda mais predominante, por possuir um total de $88,3 \%$ das solicitações de patentes, o que torna possível concluir que os pesquisadores da Universidade Federal de Sergipe possuem um perfil de desenvolver novas tecnologias voltadas para essas três áreas do conhecimento.

Dentro dessa perspectiva de análise pode-se destacar que as subseções que tem maior destaque são: A01N, A61K, B01J e C12P, conforme pode ser visto na Figura 5.

Figura 5 - Percentual de Patentes da Universidade Pública Federal de Alagoas de Acordo com as Subseções do IPC

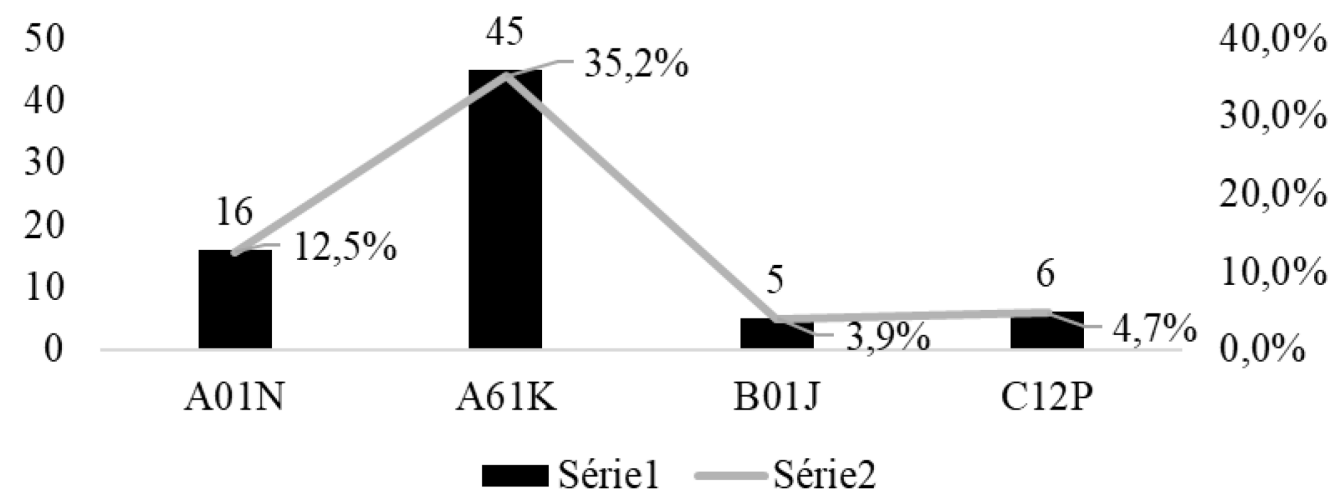

Fonte: Elaboração própria (2018).

As quatro subseções possuem um total de 72 (setenta e duas) solicitações de patentes da universidade, representando $56,3 \%$ das 128 (cento e vinte e oito) patentes, o que demonstra a existência de uma predominância de pesquisa nessas áreas. Diante disto, na Figura VI é notório a percepção que a subseção que possui maior concentração das patentes é a $A 61 \mathrm{~K}$, por ter $35,2 \%$ do total de solicitações, seguidos por: 
A01N com 12,5\%; C12P com 4,7\%; e B01J com 3,9\%. Estas representam, respectivamente, dispositivos ou métodos com finalidades médicas, farmacêuticas e odontológicas (A61K); conservação de corpos de seres humanos ou animais ou plantas ou partes dos mesmos, como exemplo, formicidas, biocidas e fungicidas $(\mathrm{A} 01 \mathrm{~N})$; processos de fermentação ou processos que utilizem enzimas para sintetizar uma composição ou composto químico (C12P); e processos químicos ou físicos, através de partículas sólidas (B01J). Ao analisar a economia do estado de Sergipe, pode-se afirmar que a condicionante de crescimento da economia esteve sempre associada aos produtos considerados comodities, como petróleo e gás natural, fertilizantes e materiais para a construção civil. A Figura 6 apresenta a divisão em termos percentuais da estrutura produtiva do estado no ano de 2015.

Figura 6 - Estrutura Produtiva do Estado de Sergipe

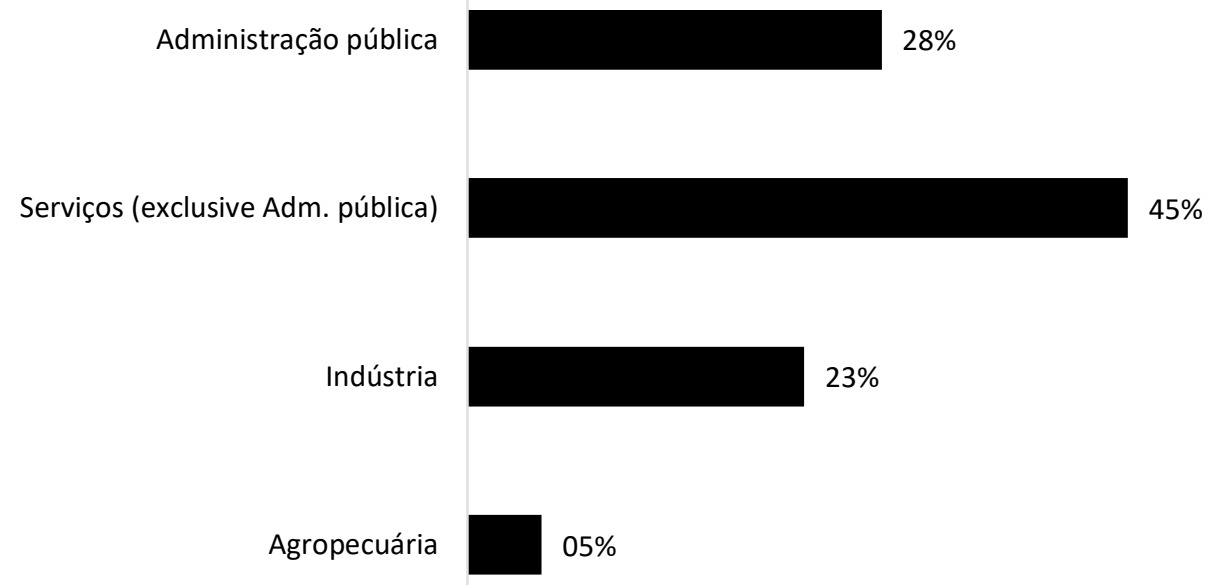

Fonte: Adaptado da SEPLAG (2015).

Ao analisar o gráfico percebe-se a estrutura produtiva do estado é predominante no setor de serviço, e incluindo a administração pública, o percentual sobe para $72,4 \%$ da estrutura econômica. No setor industrial, as áreas que se destacam são as de eletricidade e gás, água, esgoto, atividades de gestão de resíduos e descontaminação, indústrias de transformação e extrativistas, principalmente na extração de petróleo e de minerais. Além disso, o estado possui uma participação tímida no setor primário - com apenas 5\% da estrutura econômica, destacando apenas o cultivo de cana-de-açúcar. Diante do exposto, é possível afirmar que a interrelação entre a UFS e a conjuntura econômica do estado é muito incipiente, uma vez que existem pouquíssimas tecnologias desenvolvidas na universidade com vistas ao mercado, trazendo luz apenas às classificadas como $\mathrm{A} 01 \mathrm{~N}$, que poderiam ser utilizadas na agricultura ou nas indústrias de fertilizantes.

\subsection{Análise das patentes no estado de Piauí}

A Universidade Federal do Piauí (UFPI) possui 5 (cinco) campi no estado, com 65 (sessenta e cinco) solicitações de patentes publicadas sob sua titularidade, sendo que não tem patentes concedidas. Na Figura 7 é apresentado esse total de solicitações classificadas de acordo com IPC. 
Figura 7 - Número de Patentes da Universidade Pública Federal do Piauí de acordo com a Classificação Internacional de Patentes

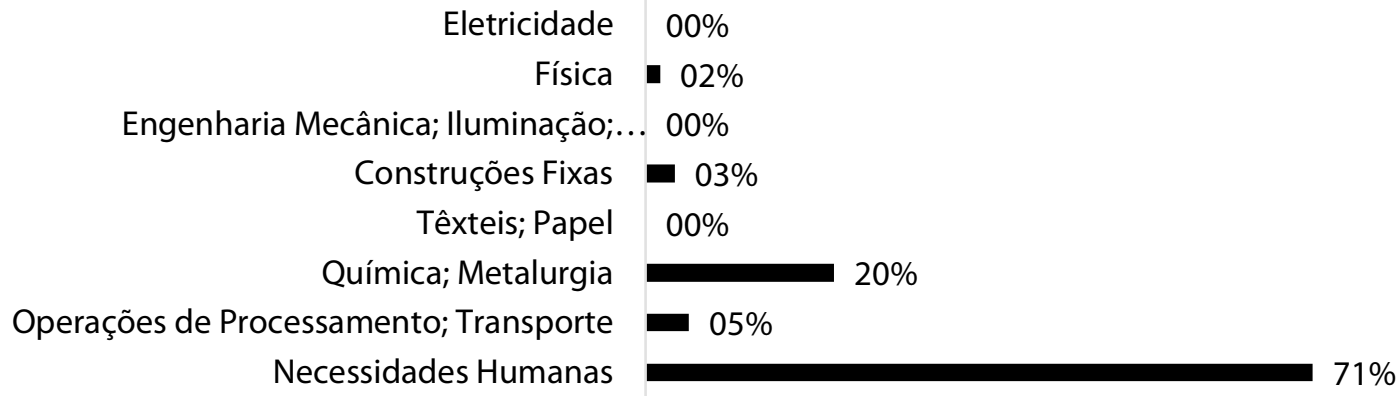

Fonte: Elaboração própria (2018).

Na UFPI, a Seção A - Necessidades Humanas tem a maior concentração de solicitações de patentes da universidade, com um total de 70,8\%, o que leva a concluir que existe uma predominância nessa área de pesquisa e que esta instituição segue os passos das outras universidades já citadas. Dentro desse aspecto de análise, é importante informar que as subseções que possuem maiores quantidades de patentes são: $A 61 \mathrm{~K}$; A23L; e, C07C, conforme pode ser visto na Figura 8.

Figura 8 - Percentual de Patentes da Universidade Pública Federal do Piauí de Acordo com as Subseções do IPC

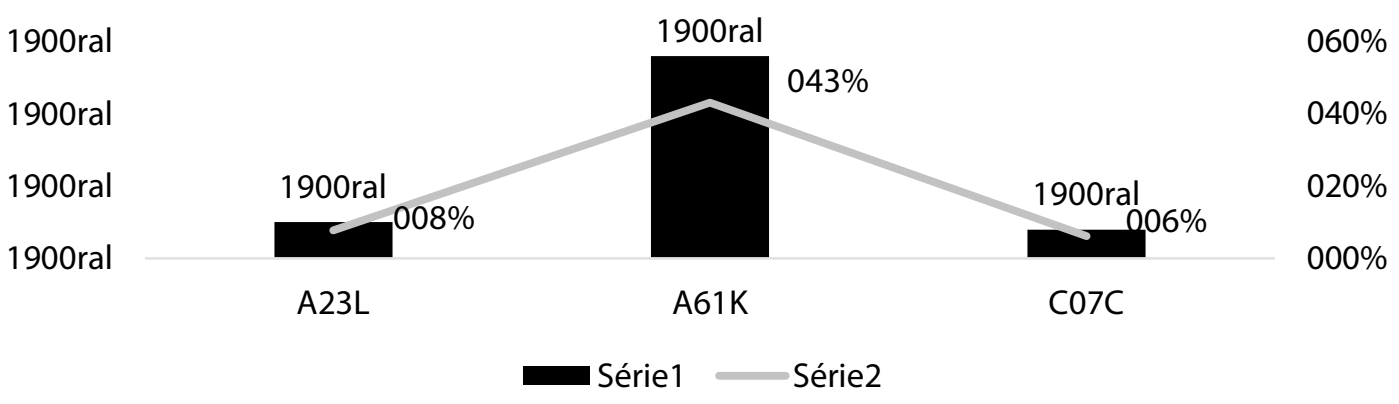

Fonte: Elaboração própria (2018).

Algumas considerações são importantes na análise das patentes dessa universidade. As três subseções possuem 37 (trinta e sete) patentes, representando 56,92\% do total de patentes da universidade, o que mostra que a instituição possui uma tendência de desenvolvimento de novas tecnologias em dispositivos para finalidades médicas $(A 61 \mathrm{~K})$, mas também no preparo, tratamento ou conservação de produtos alimentícios (A23L), bem como pesquisas voltadas para a química orgânica, especialmente em compostos acíclicos ou carbocíclicos (C07C). Analisando a economia do estado, é possível afirmar que conjectura econômica gira em torno do comércio e serviços - incluindo a administração pública, com 78,7\% do valor adicionado do PIB estadual. Na figura 9 é apresentada a estrutura produtiva econômica do Piauí de forma setorial. 
Figura 9 - Estrutura Produtiva do Estado do Piauí

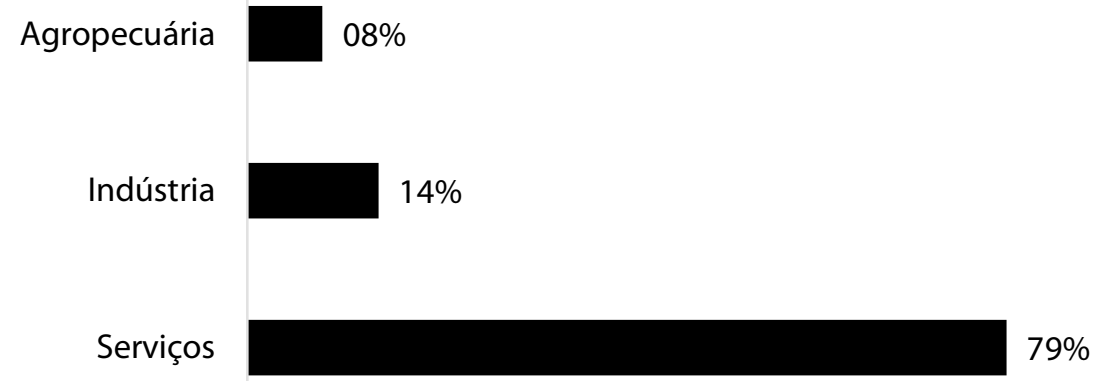

Fonte: Adaptado do CEPRO (2015).

Destrinchando a estrutura da economia piauiense, conclui-se que a agropecuária possui uma tímida participação no PIB da região. Apesar do estado ter uma produção agrícola significativa de cereais, leguminosas e oleaginosas, o que lhe confere uma posição entre os primeiros na produção agrícola da região nordeste, principalmente no cultivo de milho, soja, arroz e feijão. Ademais, a indústria ainda é pouco desenvolvida, com foco nas indústrias de transformação, de eletricidade e a indústria extrativista, sendo que essa última possui como principal extração o babaçu e a carnaúba, muito utilizados nas indústrias de cosmético e automotiva. No entanto, ao analisar as patentes da UFPI, é possível concluir que tal universidade não desenvolve tecnologias aplicáveis no mercado, uma vez que suas solicitações de patentes estão em desacordo com a estrutura econômica do estado. Corroborando essa afirmativa, podemos citar como exemplo o fato de a instituição possuir apenas 3 (três) solicitações de patentes voltadas para a atividade extrativista, representando assim um percentual de $4,6 \%$ do total de patentes, mostrando que não existe inter-relação com uma das principais atividades econômicas do Piauí.

\subsection{Análise das patentes no estado de Ceará}

O estado possui duas universidades, sendo elas a Universidade Federal do Ceará (UFC) e a Universidade Federal do Cariri (UFCA), sendo que, de acordo com os dados recuperados no site do INPI, foi possível identificar que todas os 119 pedidos de patentes publicados estão sob a titularidade da UFC, pois a UFCA, por ter sido criada em 2013, ainda não solicitou nenhuma patente. Além disso, apesar de possuir um quantitativo considerável de solicitações, ainda não tem patentes concedidas. Na Figura 10 é apresentado esse total de solicitações classificadas de acordo com IPC. 
Figura 10 - Número de Patentes da Universidade Pública Federal do Ceará de acordo com a Classificação Internacional de Patentes

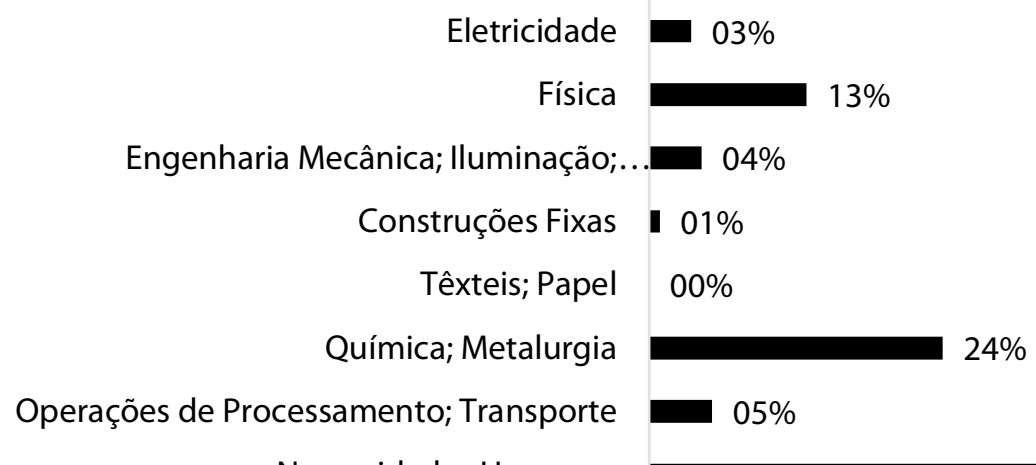

Necessidades Humanas

Fonte: Elaboração própria (2018).

Analisando o gráfico, constata-se que, apesar de ter um maior percentual na classificação A Necessidades Humanas, a universidade consegue ter uma diversificação em termos de classificação das patentes, com destaque para Seção G - Física, com 12,6\% das solicitações de patentes, o que demonstra que a UFC procura desenvolver novas tecnologias nas diferentes áreas do conhecimento. Dentro desse contexto de análise, é importante informar que as subclasses que possuem maiores percentuais de patentes são: $A 61 \mathrm{~K}$; A23L; e A21D, conforme pode ser visto na Figura 11.

Figura 11 - Percentual de Patentes da Universidade Pública Federal do Ceará de Acordo com as Subseções do IPC

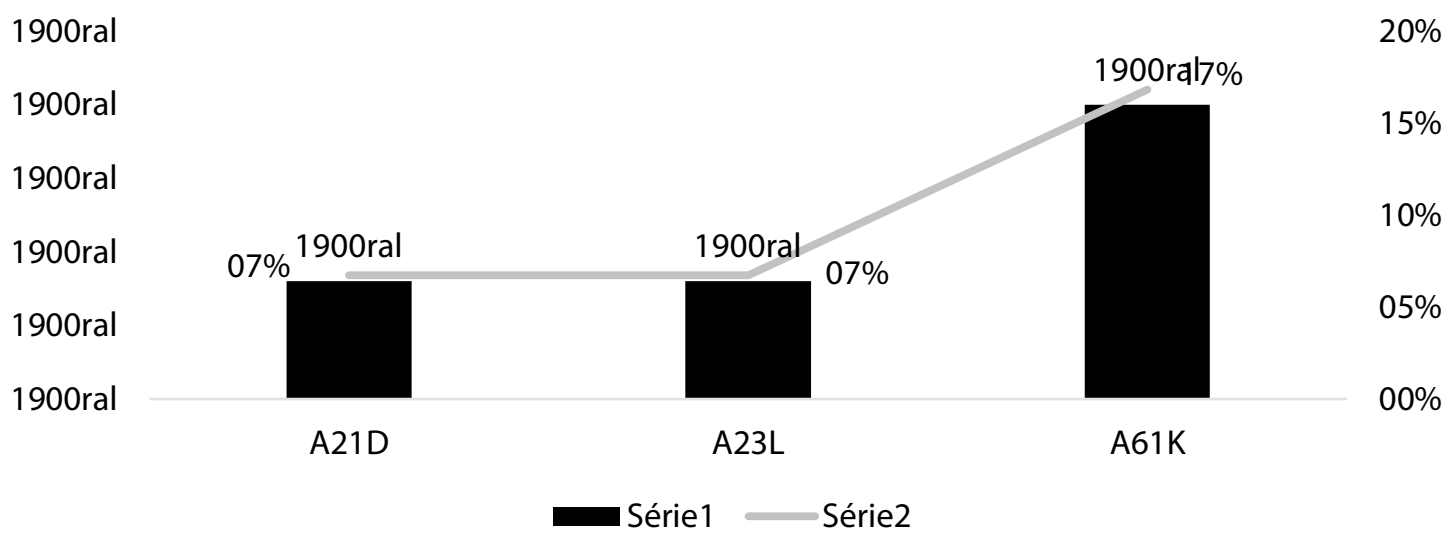

Fonte: Elaboração própria (2018).

É identificado através da análise do gráfico que a UFC, mesmo com a diversificação, possui 30,3\% de suas solicitações nessas três subclasses. No entanto, em comparação as outras universidades pesquisadas, esta possui menos patentes na subseção A61K. No que tange à economia do estado, assim como nas outras economias analisadas existe uma predominância no setor de serviços, com um total 75,95\% dos dados referentes ao ano de 2015, conforme pode ser observado na Figura 12. 
Figura 12 - Estrutura Produtiva do Estado do Ceará

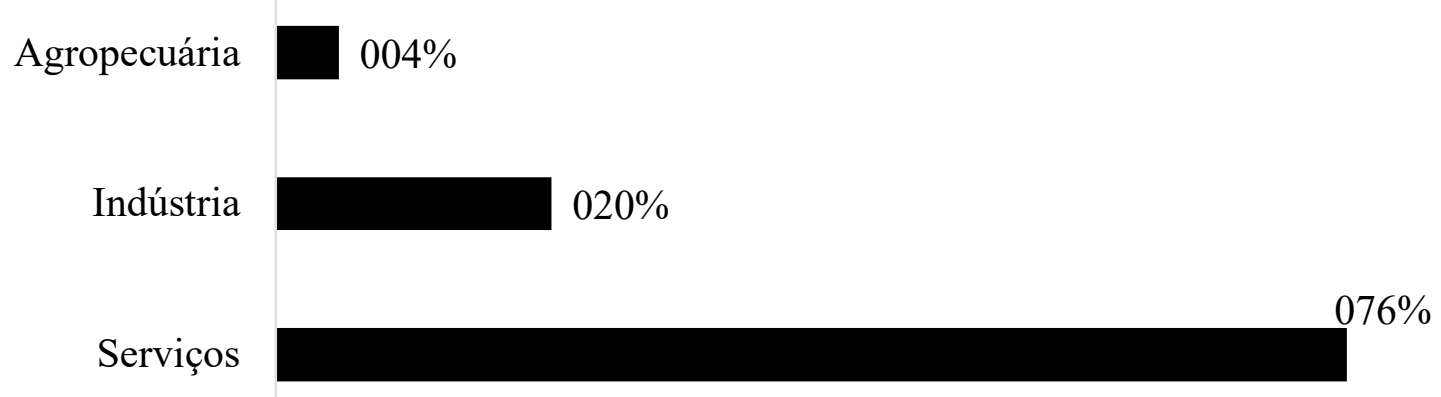

Fonte: Adaptado do IPECE (2016).

Ao relacionar a análise do gráfico à estrutura econômica cearense, é possível afirmar que apesar do estado possuir uma produção agrícola em oleaginosos, leguminosos e cereais, a participação desse setor na economia do estado ainda é pequena, talvez motivado pela escassez de recursos hídricos e pela composição de seu solo. Já em relação ao setor industrial, de acordo com os dados do IPECE, no ano de 2015 o valor adicionado bruto, ou seja, o montante que determinada atividade econômica adiciona à economia por meio de seu processo produtivo, teve um valor total de $\mathrm{R} \$ 22,4$ bilhões de reais, sendo que a indústria de transformação tem a principal posição no segmento da indústria cearense. Dentre estas, a produção de alimentos, preparação e fabricação de couros, bem como a produção de vestuário e acessórios, o que faz do Ceará um dos polos têxteis mais importantes do Brasil. Contradizendo as tecnologias desenvolvidas na universidade, uma vez que não possuem nenhuma patente na classificação D - Têxteis e papel, justamente uma das atividades econômicas de maior destaque do estado. Dessa forma, a inter-relação entre a UFC e o estado é muito baixa, porquanto, as poucas patentes classificadas como A21D poderiam ser utilizadas nas indústrias de produção de alimentos.

\subsection{Análise das patentes no estado de Pernambuco}

O estado possui 03 (três) universidades federais, sendo elas a Universidade Federal Rural de Pernambuco (UFRPE), Universidade Federal de Pernambuco (UFPE) e a Universidade Federal do Vale do São Francisco (UNIVASF). Sendo que, de acordo com os dados recuperados no site do INPI, a UFRPE possui 01 (uma) patente concedida, a UFPE possui 4 (quatro) patentes concedidas e a UNIVASF não possui nenhuma patente concedida. Na Figura 13 é exibido o total de solicitações de patentes classificadas de acordo com IPC. 
Figura 13 - Número de Patentes das Universidades Públicas Federais de Pernambuco de acordo com a Classificação Internacional de Patentes

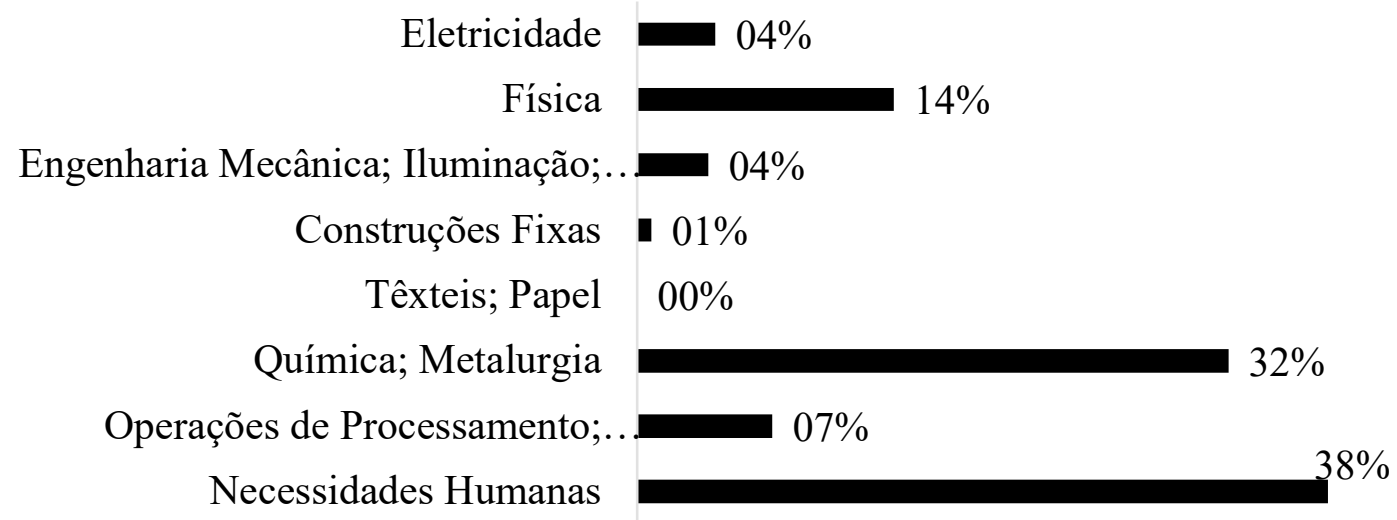

Fonte: Elaboração própria (2018).

Dentre os estados do nordeste, Pernambuco é o que possui maior número de patentes publicadas, com um total de 258, devido ao fato de que este é um dos estados mais desenvolvidos da região. Ao analisar o gráfico é possível identificar que todas essas patentes estão bem distribuídas de acordo com IPC, com um leve destaque para a classificação A - Necessidades Humanas, com 37,6\%, e a C - Química e Metalurgia, com $32,2 \%$ das solicitações de patentes, sendo que, dentro do contexto de análise das patentes, na Figura 14, é apresentado as subseções com maior número de patentes.

Figura 14 - Percentual de Patentes das Universidades Públicas Federais de Pernambuco de Acordo com as Subseções do IPC

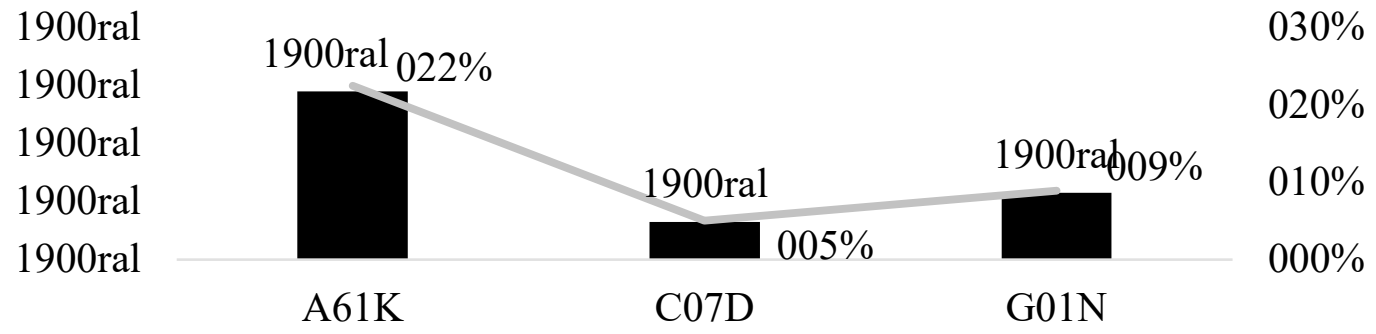

Série1 Série2

Fonte: Elaboração própria (2018).

Através da análise do gráfico é perceptível que, apesar das universidades do estado de Pernambuco possuírem solicitações de patentes em várias classificações, essas três possuem um papel relevante. Porquanto, as mesmas representam $36,43 \%$ do total de patentes, com a subseção $\mathrm{A} 61 \mathrm{~K}$ possuindo um maior número. Além desta, a subclasse CO7D (Composto heterocíclicos) tem um quantitativo significativo, com percentual de 5,04\%, tratando-se de um composto químico muito utilizado no desenvolvimento de novos medicamentos, como também o G01N (Investigação ou análise dos materiais pela determinação de suas propriedades químicas ou físicas) possuir a segunda maior quantidade de patentes com $8,91 \%$ do total. Com isso, é possível afirmar que o viés de pesquisa dessas universidades tende a pender para a área médica e o desenvolvimento de novos remédios. Em se tratando da economia pernambucana, é importante salientar que esta possui um papel de destaque no cenário nacional, motivado pelos bons índices da estrutura produtiva econômica do estado, conforme pode ser observado na Figura 15. 
Figura 15 - Estrutura Produtiva do Estado de Pernambuco

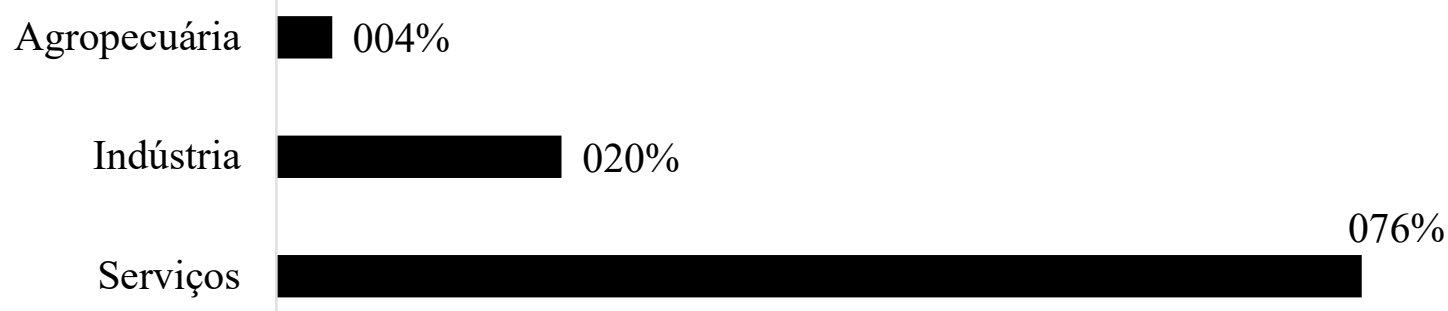

Fonte: Adaptado da Agência Estadual de Planejamento e Pesquisas de Pernambuco (2015).

Apesar do setor de serviços possuir o maior percentual, é importante destacar que a produção agrícola tem um papel fundamental na economia do estado e com foco a nível nacional, principalmente nas produções de cana-de-açúcar, mandioca, tomate, milho e feijão, além do cultivo de frutos. Acrescenta-se a criação de animais, especialmente os galináceos, por ser o segundo maior produtor da região nordeste. Por outro lado, em se tratando de setor industrial, o estado apresenta bons números, principalmente na indústria de transformação, nos segmentos automotivo, construção civil, alimentos e bebidas e na extração de petróleo. Pernambuco possui também um quantitativo significativo e diversificado na indústria, desde o setor automobilístico ao alimentício, por exemplo, o que permite ser o segundo estado de maior desenvolvimento econômico da região, perdendo apenas para o estado da Bahia.

Todavia, apesar dessa diversidade na economia pernambucana, bem como a quantidade de empresas a nível de cenário nacional e internacional, a conexão entre as universidades e o setor produtivo é muito baixo, ficando a cargo dessa interação as poucas patentes que podem ser utilizadas no agronegócio ou na indústria, pois a grande maioria das solicitações de patentes trata-se de pedidos na área médica, farmacêutica e no desenvolvimento de remédios, o que contrapõem a linha econômica do estado.

\subsection{Análise das patentes no estado de Maranhão}

De acordo com os dados recuperados no INPI, a Universidade Federal do Maranhão (UFMA) possui a segunda menor quantidade de solicitações de patentes dentre todas as universidades pesquisadas, com apenas 54 (cinquenta e quatro) patentes publicadas, mesmo tratando-se de uma instituição que possui 65 (sessenta e cinco) anos de fundação. Acrescenta-se a isso o fato de ainda não possuir a concessão de uma patente. Ao analisar a Figura 16, é perceptível que existe um agrupamento na Seção A - Necessidades Humanas, com um total de $77,8 \%$ do quantitativo das patentes.

Figura 16 - Número de Patentes da Universidade Pública Federal do Maranhão de acordo com a Classificação Internacional de Patentes

\begin{tabular}{r|c} 
Eletricidade & $00 \%$ \\
Física & $04 \%$ \\
Engenharia Mecânica; Iluminação;... & $02 \%$ \\
Construções Fixas & $00 \%$ \\
Têxteis; Papel & $00 \%$ \\
Química; Metalurgia & 13\%
\end{tabular}


Dessa forma, após a análise do gráfico, é possível afirmar que existe uma tendência de pesquisas nessa área de classificação com uma certa margem de diferença entre as outras classificações. Além disso, na Figura 17 é externado que essa maior contribuição para a classificação $A$ trata-se da subseção $A 61 \mathrm{~K}$, por possuir um total de $62,96 \%$, sendo que está bem distante da subseção $C 12 \mathrm{Q}$ (Processos de medição ou ensaio envolvendo enzimas, ácidos nucleicos ou micro-organismos) que vem logo em seguida.

Figura 17 - Percentual de Patentes da Universidade Pública Federal do Maranhão de Acordo com as Subseções do IPC

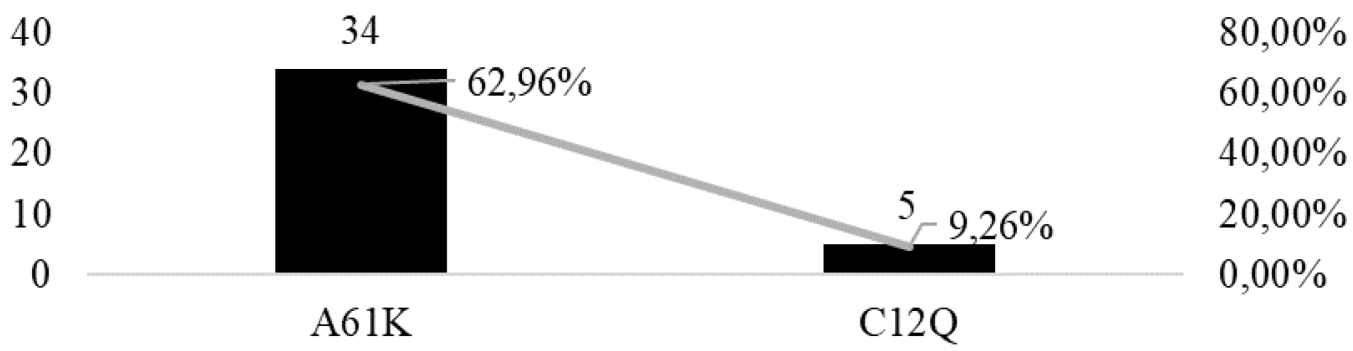

- Série1 $\longrightarrow$ Série2

Fonte: Elaboração própria (2018).

Com referência à análise econômica do estado do Maranhão, a participação da distribuição setorial no valor adicionado bruto por atividades econômicas no ano de 2015 ficou distribuída conforme apresentado na Figura 18. Acompanhados pelos outros estados, o setor econômico que possui maior percentual é o de serviços, incluindo a administração pública, sendo que o setor agropecuário, com participação de 10,4\%, tem uma presença tímida na composição do PIB do Maranhão.

Figura 18 - Estrutura Produtiva do Estado do Maranhão

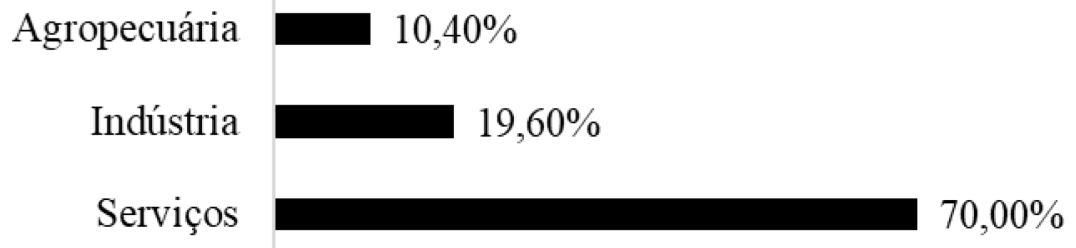

Fonte: Adaptado do IMESC (2017)

Em decorrência da análise da estrutura econômica do Maranhão e das patentes depositadas e publicadas pela UFMA, é possível ratificar que não existe uma inter-relação entre o que está sendo desenvolvido na universidade e o setor privado, especialmente a indústria. Porquanto, a indústria de transformação é a base do setor no estado, principalmente as empresas de celulose, papel e produtos de papel, por possuírem 59,6\% do total de indústrias residentes no estado, segundo o IMESC. Assim, corroborando com esse pensamento, está o fato da universidade não possuir nenhuma patente na classificação D - Têxteis e papel. 


\subsection{Análise das patentes no estado de Rio Grande do Norte}

A Universidade Federal Rural do Semi-Árido (UFERSA) e a Universidade Federal do Rio Grande do Norte (UFRN) são as duas instituições de ensino do estado. Juntas, possuem o total de 146 (cento e quarenta e seis) patentes, sendo que somente a UFRN possui patentes concedidas. A Figura 19 demonstra esse quantitativo de acordo com a classificação internacional de patentes.

Figura 19 - Número de Patentes das Universidades Públicas Federaisdo Rio Grande do Norte de acordo com a Classificação Internacional de Patentes

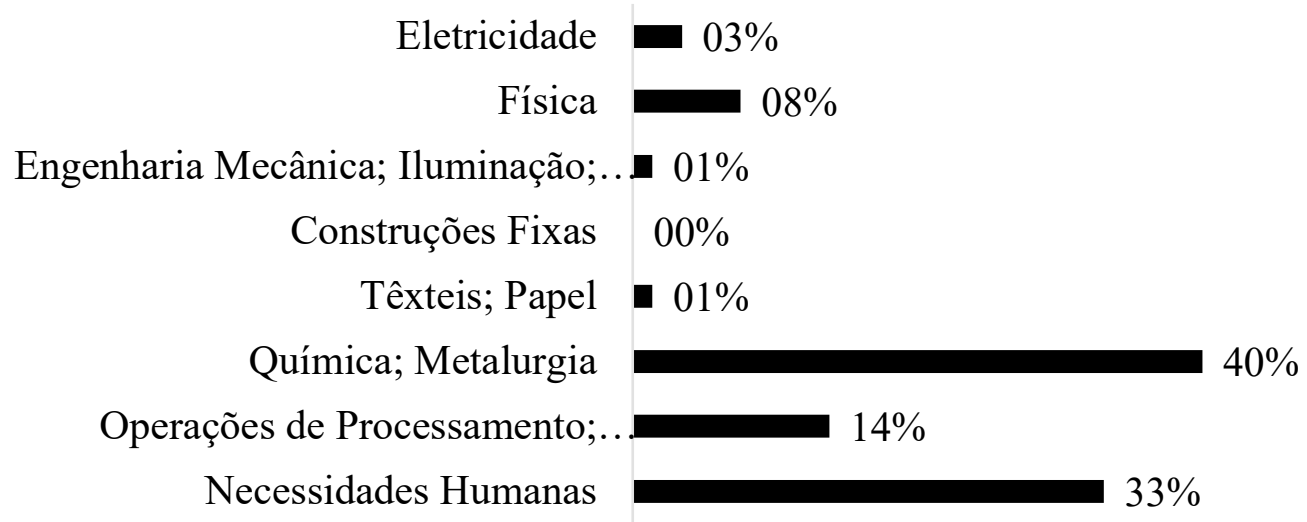

Fonte: Elaboração própria (2018).

Identifica-se através da análise do gráfico que, diferente das outras universidades já citadas, a classificação que possui maior percentual é C - Química e Metalurgia, com um total de 39,7\%, seguido seção A - Necessidades humanas, com 32,9\%. No entanto, ao analisar as subseções, constate-se que a subclasse $A 61 \mathrm{~K}$ tem uma patente a mais do que a subseção C04B (Cal; magnésia; escória; cimentos; e suas composições) e seguido da A61B (Diagnóstico; cirurgia; e identificação), conforme apresentado na Figura 20.

Figura 20 - Percentual de Patentes das Universidades Públicas Federais do Rio Grande do Norte de Acordo com as Subseções do IPC

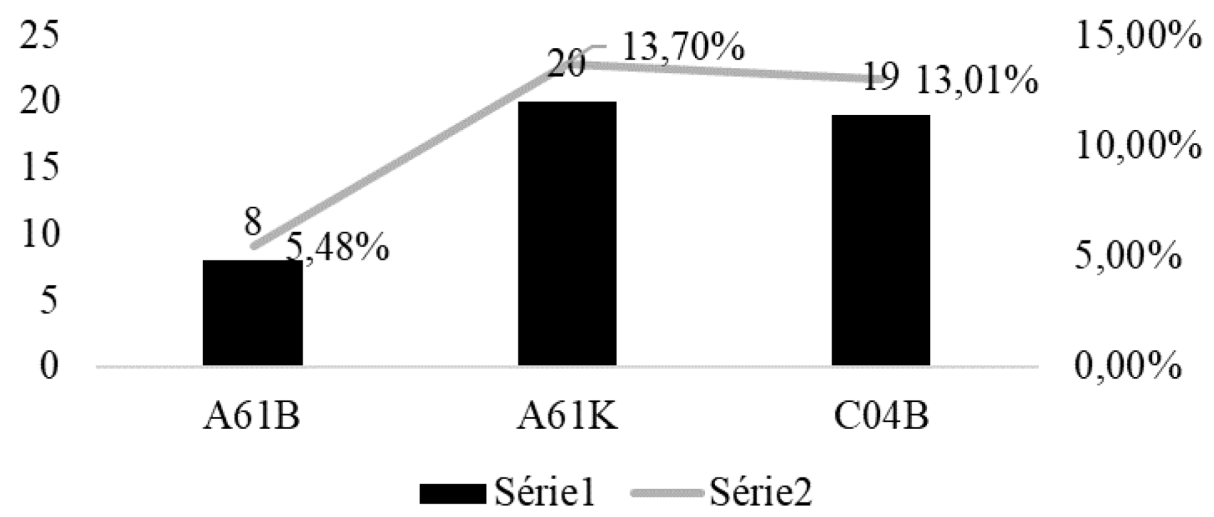

Fonte: Elaboração própria (2018). 
A conjuntura econômica do estado do Rio Grande do Norte no ano de 2015, assim como os demais estados, possui uma predominância no setor de serviços com um percentual de $75,8 \%$, conforme pode ser observado na Figura 21.

Figura 21 - Estrutura Produtiva do Estado do Rio Grande do Norte

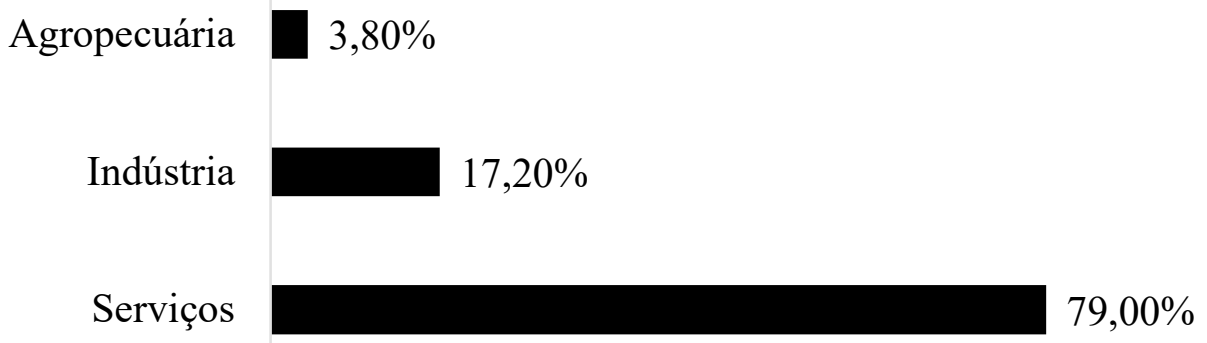

Fonte: Adaptado Instituto de Desenvolvimento Sustentável e Meio Ambiente (2015).

No que tange à agricultura, esta é bem diversificada, com foco para o cultivo de arroz, algodão, feijão, fumo, mamona, cana-de-açúcar e frutas. Já em relação à indústria os destaques ficam por produtos como: têxteis, bebidas, agroindústrias e indústrias de automóvel, além de uma indústria petrolífera forte no estado, uma vez que este é um dos maiores produtores de petróleo em terra. Logo, partindo do exposto, a interrelação entre o setor produtivo e as patentes das universidades é baixa, pois poucas patentes da UFERSA e da UFRN teriam demanda no setor privado, demonstrando a necessidade de uma maior interação.

\subsection{Análise das patentes no estado de Paraíba}

O estado tem a Universidade Federal da Paraíba (UFPB) e a Universidade Federal de Campina Grande (UFCG) e ambas possuem um total de 117 (cento e dezessete) solicitações de patentes, no entanto, ainda não possuem patentes concedidas. Abaixo são apresentadas essas solicitações de acordo com a classificação internacional de patentes.

Figura 22 - Número de Patentes das Universidades Públicas Federais da Paraíba de acordo com a Classificação Internacional de Patentes

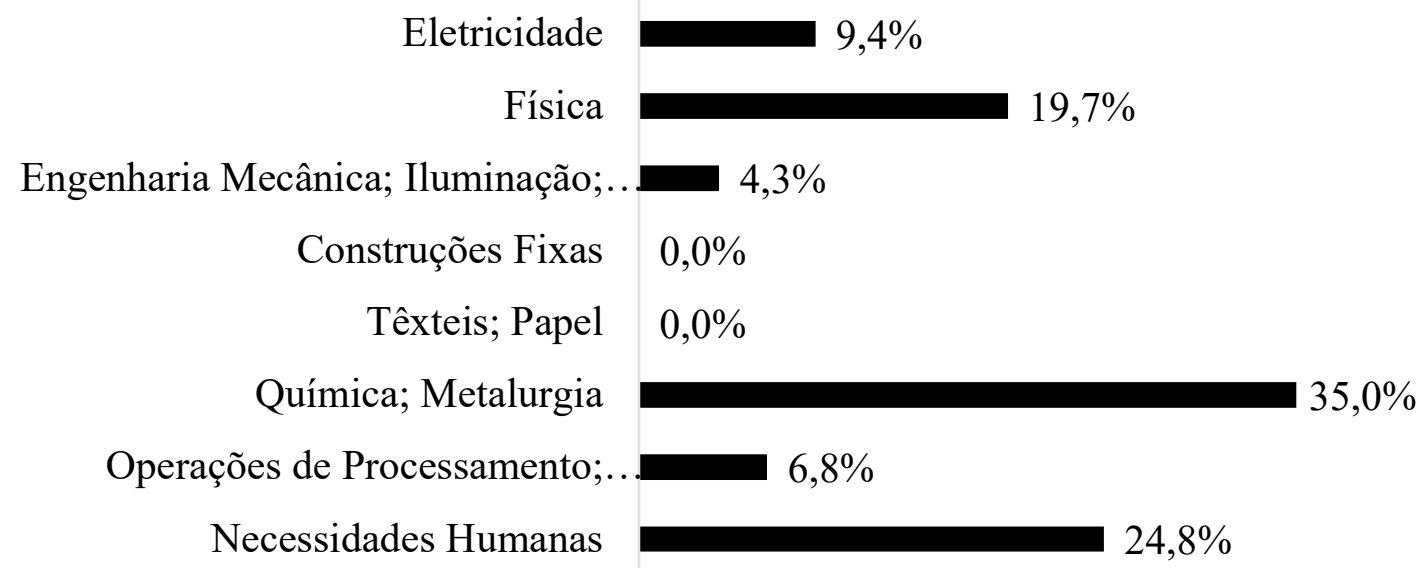

Fonte: Elaboração própria (2018). 
É perceptível que, diferente das outras universidades, a classificação que possui maior relevância é o C - Química e Metalurgia, isso mostra que possivelmente os pesquisadores dessas instituições procuram desenvolver tecnologias alinhadas a essa área. Além disso, outro ponto de destaque é o fato de existir um percentual significativo na seção G - Física, evidenciando que existem pesquisas em uma área do conhecimento que é pouco explorada pelas outras universidades da região nordeste.

Figura 23 - Percentual de Patentes das Universidades Públicas Federais Paraíba de Acordo com as Subseções do IPC

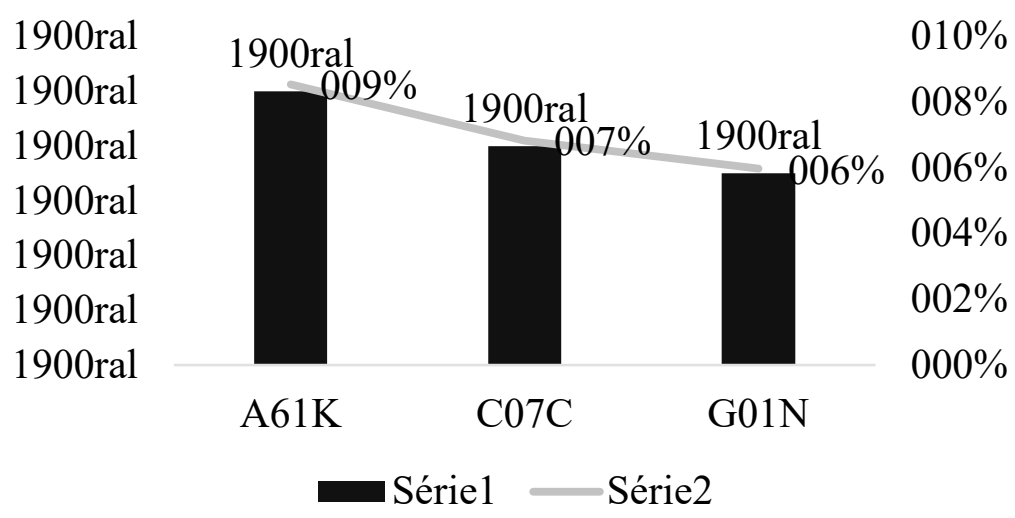

Fonte: Elaboração própria (2018).

Ao analisar o gráfico, um dado que chama atenção é o fato de a subseção A61K possuir um quantitativo de patentes inferior às outras instituições de ensino. Isto revela que a UFPB e UFCG possuem uma tendência de diversificar suas pesquisas tecnológicas. Ao analisar a estrutura econômica do estado em busca de inter-relação entre as patentes das universidades e o setor privado, é possível identificar que, apesar de tais instituições procurarem desenvolver tecnologias diversificadas, a interação é muito baixa. Porquanto, os setores industriais de maiores destaques no estado são: construção civil, couro e calçado, alimentos e minerais não metálicos. Sendo, portanto, atividades econômicas diversas da maioria das patentes das duas universidades. Logo abaixo, na Figura 24, é apresentada a estrutura econômica da Paraíba.

Figura 24 - Estrutura Produtiva do Estado da Paraíba

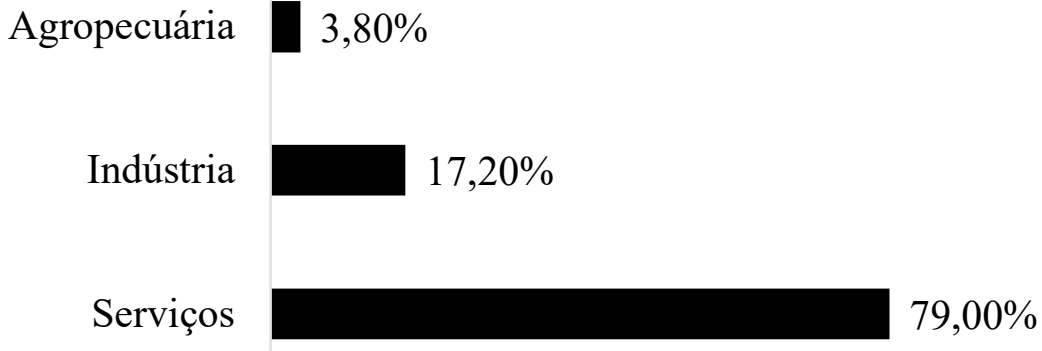

Fonte: Adaptado da SEPLAG (2015). 


\subsection{Análise das patentes no estado de Bahia}

O estado baiano é que mais detém universidades federais na região nordeste, com um total de 5 (cinco), sendo UFOB, UFSB, UNILAB, UFBA e UFRB. Porém, apenas estas duas últimas possuem solicitações de patentes junto ao INPI, com um total de 132 (cento e trinta e duas) patentes publicadas e sem concessão de patentes.

Figura 25 - Número de Patentes das Universidades Públicas Federais da Bahia de acordo com a Classificação Internacional de Patentes

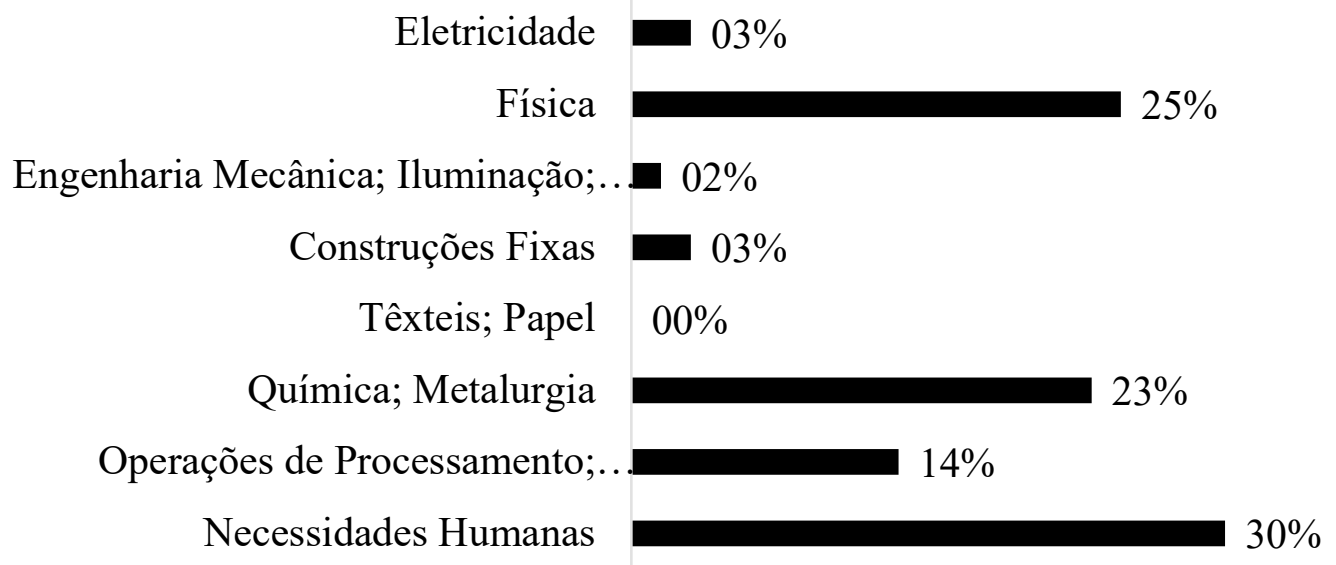

Fonte: Elaboração própria (2018).

É notório que existe uma leve superioridade em quantidade de patentes na classificação A Necessidades Humanas. No entanto, fica evidente que existe uma diversificação em outras áreas, especialmente C - Química e Metalurgia e G - Física, com respectivamente 23,5\% e 25\% do total de solicitações. Abaixo segue a Figura 26, apresentando as três maiores subseções. Assim, identifica-se que a subclasse que possui maior quantidade é a G01N, que trata da investigação ou análise dos materiais pela determinação de suas propriedades químicas ou físicas, ou seja, processos de medição ou teste, outros que não ensaios imunológicos, envolvendo enzimas ou micro-organismos. Em seguida, com 15 patentes, está a subseção A61K, que envolve dispositivos ou processos com finalidades médicas, odontológicas e farmacêuticas.

Figura 26 - Percentual de Patentes das Universidades Públicas Federais Bahia de Acordo com as Subseções do IPC

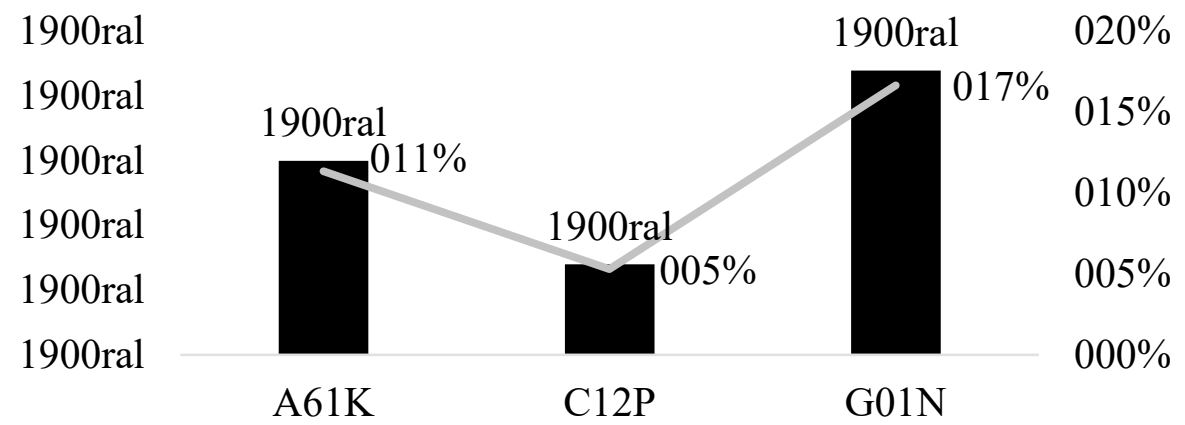

- Série1 Série2

Fonte: Elaboração própria (2018). 
Em termos da conjuntura econômica, o estado da Bahia é a economia mais forte da região nordeste, configurando entre as principais do país. O que torna essa economia forte é o fato de ser bastante diversificada, com atuação na agropecuária, serviços, indústria e até mesmo no turismo, sendo que as representações em percentuais na participação do PIB dessas atividades podem ser observadas na Figura 27.

Figura 27 - Estrutura Produtiva do Estado da Bahia

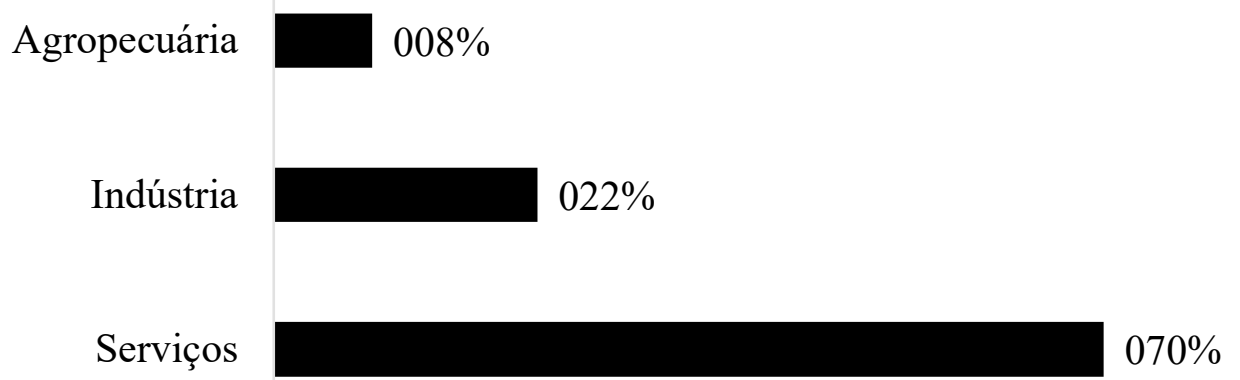

Fonte: Retirado da Superintendência de Estudos Econômicos e Sociais da Bahia (SEI), (2015).

No que tange às atividades econômicas, pode-se destacar na agropecuária a produção de cacau, sisal, mamona, coco, feijão, soja e mandioca, além da criação de caprinos. Na indústria extrativista, aponta-se a exploração de petróleo, além da extração de metais como ouro, cobre, magnesita, cromita, sal-gema, barita, manganês, chumbo e talco. Acrescenta-se ainda as indústrias de roupas, máquinas, automóveis, alimentos industrializados, eletrônicos e química, sendo a última um dos carros-chefes da economia baiana, principalmente com a localização do polo petroquímico na região metropolitana de Salvador. Diante dessa diversidade em atividades econômicas, pode-se afirmar que dentre as universidades da região nordeste, as instituições de ensino da Bahia, especialmente a UFBA, são as que possuem uma maior quantidade de solicitações de patentes que permitem a transferência de tecnologia e posterior comercialização, principalmente as que estão ligadas de forma direta ou indireta com a indústria petroquímica. Todavia, é válido ressaltar que, mesmo diante dessa possível conexão entre o setor público e privado, ainda existem algumas barreiras, tais como: a segurança jurídica, devido o fato da universidade não ter nenhuma concessão de patentes, o sistema burocrático da administração pública e falta de diálogo entre esses dois setores.

\section{CONCLUSÃO}

Este artigo buscou analisar se as patentes depositadas pelas universidades públicas federais da região nordeste do Brasil possuem relação com o mercado. Ficou constatado que a busca por informação e inovação tecnológica é uma tendência mundial que vem sendo vivenciada também na maioria das universidades públicas federais brasileiras, principalmente no que tange ao desenvolvimento de novas tecnologias, sendo que o marco para o aumento de pesquisas tecnológicas, bem como a sua facilitação no processo de transferência tecnológica, se deu no Brasil a partir da promulgação da Lei de Inovação e Tecnologia.

Sendo assim, ao longo deste artigo foram discutidos conceitos relacionados à propriedade intelectual, especificamente patente, com ênfase na análise do setor produtivo. Diante deste contexto, o presente trabalho destacou que, apesar das instituições de ensino solicitarem patentes, ficou evidente que estas não procuram dialogar com o mercado. Dessa forma, não existe ou é incipiente a interação entre o setor produtivo e as instituições. Cabe ressaltar que, apesar do fim social das universidades, faz-se necessário que estas estejam alinhadas com as demandas do mercado. Dessa maneira, é imprescindível desenvolver tecnologias que possam ser patenteáveis e comercializáveis. Porquanto, até o ponto que ocorra a transferência de tecnologia, tais patentes tornam-se ativos que geram custos para os cofres públicos. 


\section{REFERÊNCIAS}

AB AZIZ, Kamarulzaman, HARRIS, Hezlin, AB AZIZ, Nor A. Intellectual property valuation decision support system for university research output: a conceptual model. Communications of the IBIMA, King of Prussia, $v$. 2012, n. 1, p. 1 - 17, 2012.

ANDRADE, H. S.; CHAGAS JR, M. F.; URBINA, L. M. S.; SILVA, M. B. Application of a Process Model for the Management of Intellectual Property in a Technology Licensing Office from a Brazilian Research Center. International Journal of Innovation, São Paulo, v. 5, n. 3, p. 1-19, 2017.

ALAGOAS. Secretaria de Estado do Planejamento, Gestão e Patrimônio. Alagoas em Mapas 2014 [online]. Disponível em: http://dados.al.gov.br/dataset/a6504404-4b0a-47c4-a907-ae5645105ccd/resource/f999b3bab09c-43da-b58d-c80bd1dff3d3/download/alagoasemmapas2014edicao02.pdf. Acesso em: 2 jun. 2018.

BAHIA. Superintendência de Estudos Econômicos e Sociais da Bahia (SEI). PIB dos Municípios baianos [online]. Disponível em:

http://www.sei.ba.gov.br/index.php?option=com_content\&view=article\&id=2577:sei-divulga-dados-dospib-dos-municipios-baianos\&catid=10\&ltemid=565. Acesso em: 25 jun. 2018.

BRASIL. Lei 10.973, de 02 de dezembro de 2004. Regula e incentiva a inovação e à pesquisa científica e tecnológica. Diário oficial da República Federativa do Brasil. Poder Executivo, Brasília, DF, 02 de dezembro de 2004.

BRASIL. IBGE. Instituto Brasileiro de Geografia e Estatística. Produto Interno Bruto dos Municípios, base 2010 - 2015 [online]. Disponível em: https://www.ibge.gov.br/estatisticas-novoportal/economicas/contasnacionais/9088-produto-interno-bruto-dos-municipios.html?=\&t=resultados. Acesso em: 19 jun. 2018.

BRITTES, José L. P., SALLES FILHO, Sergio L. M., PEITZNER, Mariana S. Modelo e ferramenta de gestão estratégica da propriedade intelectual: estudo de caso e aplicação em uma empresa de saneamento. Qualitas Revista Eletrônica, João Pessoa, v. 17, n. 2, p. 112 - 131, maio/ago. 2016.

CEARÁ. Secretaria do Planejamento e Gestão do Estado do Ceará. Indicadores Econômicos do Ceará 2016 [online]. Instituto de Pesquisa e Estratégia Econômica do Ceará (IPECE). Disponível em: http://www.ipece.ce.gov.br/publicacoes/Indicadores_Economicos_2016.pdf. Acesso em 12 jun. 2018.

CERVO, Amado L. BERVIAN, Pedro A. SILVA, Roberto da. Metodologia científica. 6. ed. São Paulo: Pearson Prentice Hall, 2007.

FUJINO, Asa; STAL, Eva. Gestão da propriedade intelectual na universidade pública brasileira: diretrizes para licenciamento e comercialização. Revista de Negócios, v. 12, n. 1, p. 104 - 120, jan./mar. 2007.

GARNICA, Leonardo A.; TORKOMIAN, Ana L. V. Gestão de tecnologia em universidades: uma análise do patenteamento e dos fatores de dificuldade e de apoio a transferência de tecnologia no Estado de São Paulo. Gestão \& Produção, v. 16, n. 4, p. 624 - 638, out./dez. 2009.

INPI, Instituto Nacional de Propriedade Intelectual. Base de patentes. Disponível em. www.inpi.gov.br/. Acesso em: 4 mai. 2018.

LOIOLA, Elisabeth; MASCARENHAS, Tatiane. Gestão de Ativos de Propriedade Intelectual: um Estudo sobre as Práticas da Braskem S.A. Revista de Administração Contemporânea, v. 17, n. 1, p. 42 - 63, jan./fev. 2013.

MARANHÃO. IMESC. Instituto Maranhense de Estudos Socioeconômicos e Cartográficos. Boletim de Conjuntura Econômica Maranhense 2017 [online]. Disponível em: http://imesc.ma.gov.br/src/upload/publicacoes/Boletim_de_Conjuntura_final3.pdf. Arquivo capturado em 23 de junho de 2018. 
MARANHÃO. IMESC. Instituto Maranhense de Estudos Socioeconômicos e Cartográficos. Produto Interno Bruto do Estado do Maranhão: período 2010 a 2015 [online]. Disponível em: http://imesc.ma.gov.br/src/upload/publicacoes/DivulgacaoPIB_2015.pdf. Arquivo capturado em 23 de junho de 2018.

MINAYO, Maria C. S. Pesquisa social: Teoria, método e criatividade. Petrópolis: Ed. Vozes, 2002.

PARAÍBA. Secretaria de Planejamento, Orçamento e Gestão. Relatórios de atividades [online]. Disponível em: file:///C:/Users/jair.almeida/Downloads/RELAT\%C3\%93RIO+DE+ATIVIDADES_IDEME_2015.pdf.PDF. Arquivo capturado em 25 de junho de 2018.

PERNAMBUCO. Agência Estadual de Planejamento e Pesquisas de Pernambuco. Base de Dados do Estado 2015 [online]. Disponível em:

http://www.bde.pe.gov.br/visualizacao/Visualizacao_formato2.aspx?codFormatacao=1569\&Codlnformacao $=1300 \&$ Cod=3. Arquivo capturado em 23 de junho de 2018.

PERNAMBUCO. Agência de Desenvolvimento Econômico de Pernambuco. Invest in Pernambuco 2018 [on line]. Disponível em: http://www.investinpernambuco.pe.gov.br/web/invest/grandes-empresas-no-estado. Arquivo consultado em 23 de junho de 2018.

PIAUÍ. CEPRO. Fundação Centro de Pesquisas Econômicas e Sociais do Piauí. Conjuntura Econômica e Social, Boletim Analítico Anual, 2017 [online]. Disponível em:http://www.cepro.pi.gov.br/download/201804/CEPRO16_e97cc81a1d.pdf. Arquivo capturado em 19 de junho de 2018.

PIAUÍ. CEPRO. Fundação Centro de Pesquisas Econômicas e Sociais do Piauí. Produto Interno Bruto do Piauí 2015 [online]. Disponível em:http://www.cepro.pi.gov.br/download/201711/CEPRO23_a076b68dc8.pdf.Arquivo capturado em 19 de junho de 2018.

PRODANOV, Cleber C.; FREITAS, Ernani C. de. Metodologia do trabalho científico [recurso eletrônico]: métodos e técnicas da pesquisa e do trabalho acadêmico. 2. ed. Novo Hamburgo: Ed. Feevale, 2013.

RIO GRANDE DO NORTE. Secretaria de Estado do Planejamento, Gestão e Patrimônio. Produto Interno Bruto dos Municípios de Sergipe 2015 [online]. Disponível em:

http://www.observatorio.se.gov.br/images/PIB_Municipal/Relatorio_PIB_Municipal_2015_vf_17_04.pdf. Arquivo capturado em 19 de junho de 2018.

SERGIPE. Instituto de Desenvolvimento Sustentável e Meio ambiente do RN. Produto Interno Bruto do Estado e dos Municípios do Rio Grande do Norte 2010 - 2015 [online]. Disponível em: http://www.adcon.rn.gov.br/ACERVO/idema/DOC/DOC000000000171454.PDF. Arquivo capturado em 25 de junho de 2018. 